\title{
Representing Popov v Hayashi with Dimensions and Factors
}

\author{
T. J. M. Bench-Capon \\ Department of Computer Science, University of Liverpool, Liverpool, L69 3BX, UK \\ E-mail:tbc@csc.liv.ac.uk
}

\begin{abstract}
Modelling reasoning with legal cases has been a central concern of AI and Law since the 1980s. The approach which represents cases as factors and dimensions has been a central part of that work. In this paper I consider how several varieties of the approach can be applied to the interesting case of Popov $v$ Hayashi. After briefly reviewing some of the key landmarks of the approach, the case is represented in terms of factors and dimensions, and further explored using theory construction and argumentation schemes approaches.
\end{abstract}

\section{Introduction}

One of the distinctive features of legal reasoning, especially in Common Law jurisdictions such the US and UK, but relevant also to Civil Law jurisdictions, is the use of precedent cases in decision making. This aspect of legal reasoning has been a focus of work in Artificial Intelligence and Law, and approaches to this problem based on dimensions and factors have been one of the major successes of that field.

In this paper I will first describe some of the key work which uses dimensions and factors to model reasoning with legal cases. In Section 3, I will then illustrate these approaches, and some of the differences between them, using the case of Popov $v$ Hayashi with four much discussed cases relating to the possession of wild animals as the background precedents. The facts of these five cases are summarised at the beginning of section 3. In Section 4 I will look at Popov in terms of an approach based on the idea that reasoning with legal cases is a process of theory construction. In Section 5 I apply an reconstruction of factor based reasoning in terms of argumentation schemes to the case. Finally Section 6 offers a brief conclusion.

\section{Reasoning with Cases in AI and Law}

Every case in law is unique, offering a different set of facts to be decided. A legal decision must consider these facts in the light of the law, as established by previous cases, in order to come to a decision, for either the plaintiff or the defendant. But because there is unlikely to be a previous case which matches completely, there may well be arguments favouring both the parties. These arguments are based on relevant similarities between the current case and previous cases. Of course, the case under consideration may be more similar or less similar to past cases in a variety of different ways, and different similarities may suggest different outcomes. Perhaps the most important strand of work addressing this problem in AI and Law originates with the dimension based approach, initiated by Edwina Rissland (Rissland, 1983), which was then developed together with her student Kevin Ashley. These developments, which led to the HYPO system, are most fully reported in (Ashley, 1990). HYPO was designed in the context of US Trade Secret law, so illustrations will be taken from that domain.

In HYPO the relevant similarities each form a dimension. The idea of a dimension is that it is a relevant aspect of the case which can take a range of values, with the extreme pro-plaintiff value at one end of 
the range and the extreme pro-defendant value at the other. As one moves along the dimension, that aspect the case will become increasingly pro-defendant or increasingly pro-plaintiff. For example, the dimension Secrets-Voluntarily-Disclosed has as its value the number of outsiders to whom the secret had been disclosed. 0 is most favourable to the plaintiff, and, if there are disclosures, the more disclosure made the more this dimension favours the defendant. This dimension is applicable to all cases, but others are not, for example Bribe-Employee. Here the defendant's case is weakened if he bribed an employee, but the absence of bribery does not really help the defendant. Dimensions can be Boolean, numeric or a range of qualitative descriptors.

HYPO then deploys cases using a form of Three-Ply Argumentation. An argument for one side is constructed by finding the past case with the desired outcome which most closely matches the case under consideration on the most dimensions. The other side can then reply, either by finding a counter example, a past case which matches the current case on at least as many dimensions but which has the opposite outcome, or by distinguishing the case, pointing to dimensions present in the current case but absent in the precedent, or indicating dimensions on which the current case is weaker than the precedent. In the third ply the original party can try to rebut this reply, by distinguishing the counter examples, by pointing to additional favourable dimensions, or indicating dimensions on which the current case is more favourable to his side, or citing cases which show that the weaknesses identified are not fatal to his position. HYPO was especially designed to reflect the practice of hypothetical reasoning as used in US Supreme Court Oral argument, in which hypothetical cases weakening or strengthening the case along particular dimensions are used to test the robustness of the account taken of the dimensions in the decisions.

After HYPO, Ashley used these ideas as the basis of the CATO system, developed with his student, Vincent Aleven, and most fully reported in (Aleven, 1997). CATO was particularly designed to aid the teaching of law students, especially to help them to learn how to distinguish cases effectively. With this change in motivation, CATO replaced dimensions with the simpler notion of factors. Factors can be seen as being particular points on a dimension, and they are always taken as favouring either the plaintiff or the defendant. For example if the defendant had bribed an employee, that would be a plaintiff factor. If the secret had been disclosed to outsiders, that would be a defendant factor (with the number of disclosures not considered). Cases are thus a collection of the factors present. CATO also uses the threeply argumentation. First the case with most factors in common and the desired outcome is cited. Then the other side, say the defendant, replies with either a counter example or a distinction. A counter example is a precedent with the opposite outcome and at least as many factors in common. The precedent can be distinguished either by pointing to a defendant factor present in the current case but not the precedent, or by finding a plaintiff factor present in the precedent but not the current case. Finally there is a chance to rebut, by distinguishing counter examples, or by pointing to additional factors favouring the plaintiff present in the current case. An extra feature of CATO is that the factors are arranged in a factor hierarchy, with the base level factors children of more abstract factors. Thus the factors bribed employee and obtained information by deception are both grouped under the abstract factor of malicious behaviour. Now when a case is distinguished, the distinction can be downplayed if there is a sibling of the relevant factor available. Thus if it is suggested that a precedent which has bribed employee cannot be used for a case with obtained information by deception, the distinction can be downplayed since both defendants exhibited malicious behaviour. If, however, the distinction cannot be downplayed, it carries more importance, since it relates to a clear difference between the two cases.

During the 90s there were two important developments relating to this style of representing cases. Don Berman and Carole Hafner proposed (Berman and Hafner, 1993) that in order to be able to decide between cases with competing pro-plaintiff and pro-defendant factors for which no exact precedent exists, it is sometimes necessary to consider the social purposes served by finding for a party when these factors are present. In that paper they introduced to AI and Law the wild animals cases which we will return to in Section 3. In these cases, possession of the animal is disputed, and Berman and Hafner argue that the cases are resolved according to the social purposes promoted by finding for the parties. Thus in Pierson $v$ Post providing a clear criterion which will not encourage litigation is considered more important than the social utility gained by encouraging fox hunting, whereas in Keeble v Hickergill, the economic value of 
encouraging Keeble's commercial duck hunting is considered worth promoting at the expense of a clear criterion. The other important idea was introduced by Henry Prakken and Giovanni Sartor (Prakken and Sartor, 1998). This was to reconcile the concept of factors with rule based reasoning. Their idea was to consider the case in terms of three rules:

R1 Conjunction of plaintiff factors $\rightarrow$ plaintiff

R2 Conjunction of defendant factors $\rightarrow$ defendant

R3 R1 > R2 (if the plaintiff won, otherwise R2 > R1).

The set of cases could then be represented as a collection of rules and priorities between them, and a new case could be decided by applying this rule base.

In a special issue of the AI and Law journal, several papers combined these ideas: (Bench-Capon, 2002), (Prakken, 2002) and (Sartor, 2002). Here, in various ways, the priority between the pro-plaintiff rule and the pro-defendant rule was explained in terms of what was termed values, intended to play the role of the purposes proposed in (Berman and Hafner, 1993). The significance of this move was that a preference established by a factor could be transferred to a case containing different factors relating to the same value. Thus suppose in some precedent we had the rules

R4 bribed-employee $\rightarrow$ plaintiff

R5 disclosed-to-outsiders $\rightarrow$ defendant

R6 R4 > R5

This can be related to values by deducing a preference for the value of bribed-employee (e.g. punish-improper-behaviour) over the value of disclosed-to-outsiders (e.g. encourage-efforts-to-maintainsecrecy). Thus

R6a punish-improper-behaviour > encourage-efforts-to-maintain-secrecy

Now, given a new case in which no bribery had taken place but deception, which is also improper behaviour, had been used, we would have the additional rules

R7 Deception $\rightarrow$ plaintiff

R8 $\quad$ R7 > R5

The rule R8 is justified by the fact that finding for the plaitiff when either bribed-employee or deception are present promotes the value of punish-improper-behaviour, which R6a states is preferred to encourageefforts-to-maintain-secrecy. These ideas were most fully worked out in (Bench-Capon and Sartor, 2003). That paper proposed viewing reasoning with cases as constructing a theory comprising factors, cases, rules, rule preferences and value preferences. The theory is formed from a background of cases described as sets of factors, each of which promotes some value. A number of theory construction operators were defined. Extensions to the basic theory to accommodate HYPO's dimensions and CATO's factor hierarchy were also given. These ideas were explored empirically in (Chorley and Bench-Capon, 2005), which implemented a program to automate the process of theory construction, and carried out a number of experiments to evaluate the resulting theories.

The above describes the key landmarks in the development of the dimensions and factors approach to case based reasoning in AI and Law, which we shall apply to Popov v Hayashi. There have, of course, been other approaches to representing reasoning with cases in AI and Law. In particular the notion of argumentation schemes has also been used. The leading wild animals case, Pierson v Post, has been represented using an argumentation scheme for practical reasoning (Atkinson et al., 2005), and using argument schemes within the Carneades system (Gordon and Walton, 2006). The practical reasoning scheme has also been used to represent Popov (Wyner et al., 2007). The argumentation schemes and factors approach were brought together in (Wyner and Bench-Capon, 2007), which represented the three ply argumentation of HYPO and CATO as a set of argumentation schemes. We will consider only the last of these in this paper. 


\section{Representing Popov v Hayashi}

In order to apply the dimensions and factors approach to Popov v Hayashi, we must first assemble a suitable group of precedent cases. We will use a set of cases where the possession of wild animals were in dispute. While these might not at first sight seem very relevant to a dispute about a baseball, from a property law perspective there are many similarities, and several of the cases were explicitly cited in the Popov decision ${ }^{1}$ and were an important part of the argument of Finkelman (Finkelman, 2002), which is a leading commentary of the issues in Popov. Like the wild animals, the baseball had no owner (once it left the playing area), and ownership could be established with certainty by gaining bodily possession of it.

We will use four wild animals cases. Briefly stated, the facts of these four cases and Popov are:

Keeble v Hickergill (1707). This was an English case in which Keeble owned a duck pond, to which he lured ducks, which he shot and sold for consumption. Hickergill, out of malice, scared the ducks away by firing guns. The court found for Keeble. Two arguments for Keeble are possible: that he was engaged in an economically valuable activity, and that he was operating on his own land. My reading of the decision is that his ownership of the land gave him an ownership claim to the ducks.

Pierson v Post (1805). In this New York case, Post was hunting a fox with hounds. Pierson intercepted the fox, killed it with a handy fence rail, and carried it off. The court found for Pierson. The argument was that Post had never had possession of the fox. The argument that hunting vermin is a useful activity which needs protection and encouragement formed the basis of the minority decision. In this case, because of its legal setting, the original complainant, Post, whose role corresponds to the plaintiff in the other cases, is named second. We shall, however, refer to Post as the plaintiff and Pierson as the defendant to maintain consistency of role with the other cases.

Young $v$ Hitchens (1844). In this English case, Young was a commercial fisherman who spread a net of 140 fathoms in open water. When the net was almost closed, Hitchens went through the gap, spread his net and caught the trapped fish. The case was decided for Hitchens. The basis for this was that Young had never had possession of the fish, and that it was not part of the court's remit to rule as to what constituted unfair competition.

Ghen $v$ Rich (1881). In this Massachusetts case, Ghen was a whale hunter who harpooned a whale which subsequently was not reeled in, but was washed ashore. It was found by a man called Ellis, who sold it to Rich. According to the custom and practice of the whaling industry, Ellis should have reported his find, whereupon Ghen would have identified his lance and paid Ellis a fee. The court found for Ghen, on the basis that long standing and universally accepted conventions of a particular industry should be endorsed.

Popov v Hayashi (2002). This San Francisco case concerned the possession of the baseball which was struck to give Barry Bonds his record breaking 73rd home run in the 2001 season. Such a ball was thought likely to be very valuable (Mark McGwire's 1998 70th home run ball sold at auction for \$3,000,000). When the ball was struck into the crowd, Alex Popov caught it in the upper part of the webbing of his softball glove (fans often wear baseball or softball gloves to assist in catching balls that leave the park). Such a catch, known as a snowcone catch where the ball is not fully in the mitt, does not give certainty of retaining control of the ball, particularly since Popov was stretching and may have fallen. Popov was not, however, given the chance to complete his catch since, as it entered his glove, he was tackled and thrown to the ground by others trying to secure the ball. In the ensuing scrum the ball was dislodged from the glove and picked up by Patrick Hayashi (himself innocent of the attack on Popov), who put it in his pocket, so securing possession. The incident was filmed on video by one Josh Keppel. In fact, as can be seen from the decision elsewhere in this journal, the case was not decided on the basis of the wild animals cases. The judge found this line of argument inconclusive and used a different set of cases to come to his

\footnotetext{
${ }^{1}$ Popov v. Hayashi, 2002 WL 31833731. (Cal.Superior Dec 18, 2002) (NO. 400545). The decision was given by the Honourable Kevin M McCarthy and is reprinted in this volume.
} 
decision, which was that the ball should be sold and the proceeds divided equally. In this paper we will consider only the part of the decision related to issues arising in the wild animals cases.

In the next two subsections I shall represent these cases first using factors and then dimensions, which will allow a finer grained, and hence more satisfactory, representation of the issues involved.

\subsection{Factor Based Analysis}

These cases have all been much discussed in AI and Law, as mentioned above, and so we can use this work as the basis for our representation. The first three of these cases were first discussed in AI and Law in (Berman and Hafner, 1993). Berman and Hafner identified four factors, and associated purposes.

F1 Not-Caught: The animal was neither in the bodily possession of the plaintiff, nor mortally wounded. Advances the purpose of legal certainty by providing a clear definition of possession. It is prodefendant.

F2 Own/Open: Own applies if the plaintiff was hunting on his own land and advances the purpose of protection of property rights. It is pro-plaintiff. Open applies if the plaintiff was hunting on open land and is pro-plaintiff. Only if the incident had taken place on the defendant's land would the defendant be favoured. This factor requires some discussion below.

F3 Livelihood: The plaintiff was engaged in earning his living. The purpose advanced is the protection of valuable activity, and it is pro-plaintiff.

F4 Competition: The defendant was in competition with the plaintiff. This advances the purpose of promoting free enterprise, and is pro-defendant.

These are referred to as factors in (Berman and Hafner, 1993), but the $\mathrm{Own} / \mathrm{Open}$ factor bears a stronger resemblance to a dimension ${ }^{2}$. Indeed, since Open is seen as a limit on $O w n$, it might even be thought that this was a dimension not applicable in cases where Open applied. For a strict factor based representation it might be better to consider only $O w n$, and to have no factor in the case when the land was open. There are also potential factors that are not represented by F1-F4. It was argued in Pierson that the plaintiff was engaged in useful activity, even though he was not earning a livelihood. Indeed the root of the dissent in that case was that such a socially useful activity should be encouraged, even at the expense of legal clarity. We will therefore note activity-socially-useful as a potential additional factor.

The group of papers which built on this work, (Bench-Capon, 2002), (Prakken, 2002) and (Sartor, 2002) and (Bench-Capon and Sartor, 2003), broadly adopted this analysis, but with some variations. In (Bench-Capon, 2002), five factors are used, splitting F2 into two separate factors Own (F2a) and Open (F2b). The other change is to factor F4, where instead of the defendant being in competition with the plaintiff, the factor is based on the defendant being in pursuit of his own livelihood (F5). This is more than a mere terminological change because it affects the value to which the factor relates. F5 relates to the same value as F3, whereas F4 introduced the additional value of free enterprise. Furthermore F5 would apply in cases where F4 would not. If Hickergill had been been operating a bird watching site, he would have scared the ducks for his own profit, even though not in competition with Keeble. In (Sartor, 2002) four factors are used: Sartor follows Bench-Capon in using F5 rather than F4, but omits F2b altogether. These are also the four factors used in (Bench-Capon and Sartor, 2003). In (Prakken, 2002) Prakken also uses these four factors, but also allows the absence of these positive factors to be included in the representation, effectively giving F2b and three additional factors, caught (F1b), plaintiff not pursuing livelihood (F3b) and defendant not pursuing livelihood (F5b). This means that every case can be represented using exactly four factors, which has some technical advantages in the context of (Prakken, 2002), but while F1b and F2b seem reasonably close to the spirit of factor based representation, F3b and F5b look much more like the absence of a factor than the presence of a distinct factor. The factors of (Prakken, 2002), in fact resemble four binary dimensions. We will return to dimensions later.

\footnotetext{
${ }^{2}$ This was the view of Rissland and Ashley in (Rissland and Ashley, 2002), where they explicitly say that F2 should be treated as the two extreme points on a dimension, rather than as two separate factors.
} 
For the moment let us use the factors identified so far to represent the wild animals cases. We will use both F4 and F5, since as noted above they are independent, and also will ignore Open. The cases and their factors are shown in Table 1.

Table 1 Factors in the Wild Animals Cases

\begin{tabular}{|l|l|l|l|l|l|}
\hline Case & F1 & F2 & F3 & F4 & F5 \\
\hline Pierson & Y & & & & \\
\hline Keeble & Y & Y & Y & & \\
\hline Young & Y & & Y & Y & Y \\
\hline Ghen & Y & & Y & & Y \\
\hline Popov & Y & & & Y & \\
\hline
\end{tabular}

Viewed in this way it seems rather clear that Pierson and Young are the appropriate precedents ${ }^{3}$, and that there is little that can be said for Popov, since there are no pro-plaintiff factors present. But the case was clearly not as open and shut as this would suggest, which suggests that something is missing from the analysis. In his commentary (Finkelman, 2002) Finkelman argues that the correct precedents are provided by whaling cases, including Ghen $^{4}$. The possession of home run balls is, like whaling, governed by convention: the first catcher of the ball, like the first to harpoon the whale, possesses the ball, even if he subsequently puts it down or it is jostled out of his grasp. This would suggest another factor, Convention (F6), applicable in Ghen and Popov and favouring the plaintiff. Finkelman argued that

Popov, having caught the ball, owns it, even if he later puts it down or drops it. Once having possessed it in his glove, it became his,

Unfortunately for Popov, however, McCarthy decided on the basis of the witnesses testimonies that Popov had never completed his catch, since the assault had interrupted his efforts before he had had the opportunity to do so. Since by baseball conventions it was no catch, the convention that the first catcher has possession does not apply on the facts.

It seems therefore that we need some more subtle analysis to do justice to Popov's case. We will therefore turn to dimensions to see if they can supply what is required.

\subsection{Analysis in Terms of Dimensions}

The wild animals cases have been discussed in terms of dimensions in (Rissland and Ashley, 2002) and (Bench-Capon and Rissland, 2001). In (Rissland and Ashley, 2002) Rissland and Ashley argue that F1 and F2 of (Berman and Hafner, 1993) should be treated as dimensions. F2 we have touched on already, and it does indeed seem correct that F2a and F2b should not be treated as independent, and that only when the land is owned is real weight added. The need for a dimension in the case of F1 is different: it is that the caught or not caught distinction is simply too black and white. The events leading up to catching a wild animal bring the hunter progressively closer to possession of the animal and capture becomes progressively more certain. Thus it would seem wrong to consider Young, who was about to haul in his nets, no more favourably than a fisherman who had only just started to spread his nets. And the fact that Popov, although not completing the catch did get his glove to the ball and would very likely have completed the catch had he not been interfered with, should be given some recognition. A dimension encompassing the closeness of the pursuit would allow Popov to get due credit for the actions he had taken.

The role of dimensions is developed further in (Bench-Capon and Rissland, 2001). As well as considering the different degrees of closeness to bodily possession, Bench-Capon and Rissland suggest that the key importance of land ownership (at least in cases where the question of trespass does not arise) is that the owner of the land may be considered to own the animals in virtue of their presence on his

\footnotetext{
${ }^{3}$ a suggestion supported by the fact that these were both cited in the decision on Popov.

${ }^{4}$ This case, and another similar leading whaling case were both cited in the decision.
} 
land, without any need to physically seize them. Moreover, the factors relating to livelihood seem rather narrow: they do not allow us to take account of the arguably socially useful role of Post's fox hunting, nor of the fact that the defendant in Keeble was acting out of malice. Without this we do justice neither to the strength of Post's case nor of Keeble's, and these strengths do matter in the current case. Following these suggestions we might therefore use four dimensions to represent the cases:

D1 Possession: This would range from the extreme pro-defendant position where the animal was roaming entirely free, through chase being started, hot pursuit, mortal wounding to the extreme pro-plaintiff position of actual bodily possession.

D2 Ownership: This would range from the the extreme pro-defendant position where the animals never entered the plaintiff's property, through various degrees of frequency of presence, from straying to regular and predictable visits, to the extreme pro-plaintiff position where the animal was incapable of leaving the land, where we had a fox on an island, for example.

D3 PlaintiffMotive: Rather than simply focussing on whether the plaintiff was earning his livelihood, the suggestion here is that a range of increasingly worthy motives should be considered, starting from malice, through pleasure and social service to livelihood.

D4 DefendantMotive: As for the plaintiff motive, but relating to the defendant.

This finer grained representation allows us to make some potentially important distinctions.

- In Pierson the plaintiff was in hot pursuit, had no ownership claim, was acting (perhaps) from social concern, while the defendant was also concerned to exterminate vermin ${ }^{5}$.

- In Keeble the plaintiff was trying to attract the ducks, could expect to find them on his own land, was acting from economic motives, while the defendant was acting out of malice.

- In Young, the plaintiff was on the point of securing the fish, had no claim arising from land ownership, and both parties were acting from economic motivations.

- In Ghen the plaintiff had harpooned the fish, establishing possession under whaling conventions, had no claim arising from land ownership, and both parties were acting from economic motivations, although not in competition with one another.

- In Popov the plaintiff would in all likelihood have secured the ball but for the assault, and had no claim arising from land ownership. Both parties were motivated by money, although they were not creating wealth as were Keeble, Young and Ghen, and were in competition with one another.

We can now arrange the cases on our dimensions in the following way (naming the most pro-plaintiff case on each dimension first). Note that the Ownership dimension applies only to Keeble.

- Possession Ghen, $\{$ Popov, Young $\}$, Keeble, Pierson

- Ownership Keeble,

- PlaintiffMotive $\{$ Ghen, Young, Keeble $\}$ Popov, Pierson

- DefendantMotive Keeble, Pierson, Popov, $\{$ Ghen, Young $\}$

It could be argued that Popov and Pierson should be switched with one another on both the motive dimensions, since although they were both economically motivated, their activity had no real social value. Looked at in either way, Popov seems closest to Young, Ghen being further from Popov than Young on the possession dimension. But even this level of detail, although recognising the strength that Popov derives from being so close to securing possession, does not do full justice to Popov's case, in that the interference that prevented him from taking full control of the ball was illegal: a common assault. Equally, however, it needs to be recognised (for it was so found by McCarthy) that the defendant, Hayashi, was entirely innocent of any illegality, in that he was not part of the mob which descended on Popov. Thus Popov's case is weakened in one direction and strengthened in another.

\footnotetext{
${ }^{5}$ Although it has been suggested in (Berger, 2006) that Pierson did in fact wish to interfere because of friction between the different social groups to which the landowning Post and the small holder Pierson belonged. Berger also suggests that the incident took place very close to Pierson's property and the land was less open than is usually thought.
} 
The dimensions discussed so far are all taken from analysis of the wild animal cases, which was undertaken without any thought of Popov. This is, of course, in the spirit of systems such as HYPO and CATO which presuppose a set of cases to which the current case will be presented. Suppose, however, we think instead about a representation with Popov at the forefront of our mind, which is in line with Levi (Levi, 1948), who holds that past cases are potentially reinterpreted in the process of being applied to new cases. Looking at the section of McCarthy's decision in which he discusses the evidence in order to establish the facts on which he will base his decision, we can see that he has three major concerns. He establishes that Popov did not complete his catch, and so he was never in possession of the ball. Second he is able to establish that Popov was prevented from attempting to complete the catch by an illegal action on the part of a group of unidentified persons. Third he establishes that Hayashi was not one of the people involved in the illegal act. The first of these facts relates to the dimension of Possession, and the steps taken by Popov falling short, as they do, of bodily seizure locates Popov in the same position on this dimension as Young. The other two concerns, however, do not relate to the dimensions we have identified so far, and so perhaps we should introduce new dimensions to reflect these concerns. One relates to the nature of the interference with the plaintiff. In Popov the interference was illegal, and we can see this case as being at the extreme pro-plaintiff end of this dimension. We could also locate the other cases on this dimension: in Keeble the interference was a malicious infringement of the plaintiff's enjoyment of his land; in Pierson the interference was discourteous, interfering with the plaintiff's enjoyment of a legal activity; in Young the interference can be seen as vigorous competition; and finally in Ghen the interference was a failure to obey the conventions of the whaling industry.

The third concern relates to the conduct of the defendant. In Popov and Ghen, the defendants did not themselves interfere with the plaintiff's pursuit. Hayashi, indeed was entirely blameless, whereas perhaps Rich should have checked out whether Ellis was entitled to sell the whale. The Popov case thus represents the extreme pro-defendant position, with Ghen, Young, Pierson and Keeble each being more pro-plaintiff on this dimension. An extreme pro-plaintiff case would be where the defendant had himself been responsible for illegal interference.

We can now look again at the other dimensions. Ownership of the land is clearly a relevant fact, but does it merit treatment as a dimension? Ownership has two effects: one is to make some acts of interference illegal or at least, more culpable. Interference which might be acceptable on open land becomes less so when the plaintiff is attempting to enjoy his property. Thus had Post been hunting on his own land, Pierson's act would have been illegal rather than discourteous, because he would have been trespassing. Similarly if Keeble had been hunting on open land, Hickergill's bird scaring would have been more excusable. The second element of ownership of land is the rights it gives to possession of animals found on it. Thus Keeble's claim requires the element of possession that ownership gives. So perhaps we should replace the NotCaught dimension by one relating to possession, whether this comes through bodily seizure or through land ownership or through some universally accepted convention. Bodily seizure would represent the extreme pro-plaintiff position, followed by ownership conferred through a long standing and universally recognised convention (Ghen), followed by possession in virtue of ownership of the land on which the animals are found (Keeble), followed by possession established through efforts to capture (Pierson, Young and Popov), followed by a number of increasingly pro-defendant positions not exemplified in the cases being considered.

Turning to motive, we might construct a dimension relating to whether we wished to encourage the activities of the plaintiff or the defendant. This dimension would be inapplicable or neutral in Popov and Young where both were engaged in the same activity. The dimension would strongly favour Keeble, since he is engaged in an economically useful task which Hickergill is attempting to thwart. It would also favour Ghen, since the harpooning of the whale is what matters if the whale is to be brought to market. It would favour Post, since he is systematically attempting to eliminate vermin, which is socially useful, whereas Pierson is opportunistic and would not have been able to kill the fox had it not been flushed out by Pierson and his dogs.

Our final attempt to represent the case using dimensions is thus (with pro-plaintiff first):

- Possession: Ghen, Keeble, $\{$ Young, Popov\}, Pierson 
- InterferenceIllegal: Popov, Keeble, Pierson, Young, Ghen

- DefendantBehaviour: Keeble, Pierson, Young, Ghen, Popov

- ActivityToEncourage: Ghen, Keeble, Pierson \{Young, Popov\}

Now we can construct HYPO style three ply-aguments ${ }^{6}$. For the defendant we can cite Keeble, on the grounds that Popov is stronger on the InterferenceIllegal dimension. This however can be distinguished as weaker on all three of the other dimensions. In rebuttal Ghen could be cited to show that a pro-defendant position on DefendantBehaviour is not decisive. The defendant might cite Young as the case to follow as this matches Popov on two dimensions, and is actually weaker for the defendant on DefendantBehaviour, but still found for the defendant. This case may, of course, be distinguished on InterferenceIllegal. The defendant can cite Pierson in rebuttal, since it was found for Pierson, who plays the defendant role in that case, although weaker on two of the dimensions.

\subsection{Discussion}

Thus far, we have seen that, applying the analysis of existing papers to Popov v Hayashi, we find that the factors based approach aligns the case with Pierson, and the dimensions approach with Young. Neither of these would be good news for Alex Popov, and on these analyses he would have no way of distinguishing the cited cases. If, however, we consider the perspective just developed, Popov (and Pierson) has a dimension on which Young can be distinguished: the interference was illegal. Although this was not something that the analyses is previous papers recognised, it was a clear consideration of the judge in the Popov case. Thus we can see Popov as requiring us to modify the analysis to include this additional dimension.

We should perhaps not be too surprised that a new case can lead us to reinterpret existing cases. Case law should not be seen as a static body of knowledge, but as something which evolves and adapts. For example Levi (Levi, 1948) writes:

The movement of common or expert concepts into the law may be followed. The concept is suggested in arguing difference or similarity in a brief, but it wins no approval from the court. The idea achieves standing in society. It is suggested again to a court. The court this time reinterprets the prior case and in so doing adopts the rejected idea.

The adaptive nature of case law was explored in (Henderson and Bench-Capon, 2001), where the authors considered how understanding of a case law domain would evolve differently depending on the sequence in which cases were presented.

Of course, this does have some implications for the use of systems such as HYPO and CATO: those systems presuppose that case law can be seen as a static body of analysis which can be applied to a new case without adaptation. How can we plausibly make the assumption of a static domain? First there is the nature of the domain. In Levi's model (Levi, 1948) a period of fluctuation and development is followed by a period of stability, in which the law seems to be well understood and settled. During this period, cases tend to retain a fixed interpretation. Eventually tensions will develop and this will break down, typically through a landmark case. That eventually a settled interpretation would break down was recognised, and signs that suggest that a change is imminent were discussed, in (Berman and Hafner, 1995) and (Rissland and Friedman, 1995). So one thing that HYPO and CATO require is that the law be in its period of stability. It is also necessary to recognise that any analysis will have a lifetime and then need revisiting when the understanding of the domain is changed by some landmark case. A second consideration is the granularity of the analysis. The more abstract the level of analysis, the more likely we are to be able to fit a new case into it. On the other hand, results using this coarser classification may be less reliable. The abstract factor hierarchy of CATO helps with this: one could hope that new aspects can be incorporated as leaves in the abstract factor hierarchy, while retaining the structure. This is made all the more likely in CATO, which deals with the domain of US Trade Secrets Law because, for that domain, the Restatement

${ }^{6}$ The following may fruitfully be compared with the argumentation scheme approach of section 5 . The plaintiff argument is Figure 1 and the defendant argument Figure 2. 
of Torts provides an authoritative high level set of abstract factors. This was used to structure the abstract factor hierarchy in (Aleven, 1997), and explicitly as a 'logical model' in IBP (Brüninghaus and Ashley, 2005), a system based on CATO designed to predict the outcome of cases based on the strength of the parties arguments relating to the relevant issues. Finally there is the precaution of basing the analysis on a sufficiently large number of cases: it was perhaps unrealistic to expect all the issues to be identified in the four cases we used as background here.

\section{Representation as Theory Construction}

We can use the analysis developed so far to consider the representation of Popov $v$ Hayashi in the theory construction style of (Bench-Capon and Sartor, 2003).

Following this methodology we must first identify a set of factors, the values they promote and the side they favour. In order to do this we will consider the dimensional analysis of section 2, and use the various points on these dimensions as factors. This is essentially how the factors of CATO were derived from the dimensions of HYPO. One key additional piece of interpretation is that because the factors must favour either the plaintiff or the defendant we need to say at what point on the dimension it becomes pro-defendant. Since selection of the factors to use is part of the theory construction process, we need not worry about being selective in making factors available. The side favoured will depend on how far the factor lies along the dimension, and the value will be taken from the purposes the dimension promotes. The factors are shown in Table 2. Only factors present in the five cases under consideration will be shown. We will also need to associate values with these factors. On the ownership dimension, bodily seizure, ownership of the land, and the convention governing whaling all provide clear conditions for possession, and so promote Legal Certainty. In so far as this dimension favours the plaintiff in Pierson and Popov when the factor is hot pursuit, the value seems to be that their efforts merit some Reward. The dimension relating to illegal interference seeks to encourage obedience to the law and so promotes Public Order. That the defendant should not be punished for interference in which he played no part promotes Fairness. Finally the dimension comparing motives is intended to encourage socially useful activities, and so promotes Utility.

We next assign the factors to the five cases, and record their outcome. We treat Young's interference as discourteous, since it was an ungentlemanly thing to do, even if all is fair in business.

- Keeble: $\{\mathrm{NC}, \mathrm{OL}, \mathrm{N}, \mathrm{M}, \mathrm{EV}\}$, Plaintiff

- Pierson: $\{\mathrm{NC}, \mathrm{HP}, \mathrm{ID}, \mathrm{DD}, \mathrm{SV}\}$, Defendant

- Young: $\{\mathrm{NC}, \mathrm{HP}, \mathrm{ID}, \mathrm{DD}, \mathrm{EV}\}$, Defendant

- Ghen: $\{\mathrm{NC}, \mathrm{C}, \mathrm{B}, \mathrm{EV}\}$, Plaintiff

- Popov: $\{\mathrm{NC}, \mathrm{HP}, \mathrm{A}, \mathrm{B}, \mathrm{PG}\}$, Undecided

Note that only the strongest factor is taken from a given dimension: in Keeble, for example, the ecomomic value of his pursuit subsumes any social value and the element of personal gain. Following the method of (Bench-Capon and Sartor, 2003) we begin by constructing the simplest pro-defendant theory, citing Pierson ${ }^{7}$ :

T1

cases: (Popov,(HP,A,B,PG)), (Pierson, (HP, ID, DD, SV)

factors: $\mathrm{NC}, \mathrm{HP}$

rules: $\mathrm{NC} \rightarrow$ Defendant, $\mathrm{HP} \rightarrow$ Plaintiff

rule prefs: $\mathrm{NC} \rightarrow$ Defendant $>\mathrm{HP} \rightarrow$ Plaintiff

value prefs: $L C>R$

At this point neither of the pro-plaintiff precedents are in fact useful to Popov - the only factor in common with Ghen is that the defendant was doing nothing illegal, which favours the defendant, and

${ }^{7}$ Or Young: it makes no difference in this representation since the factors actually used in $\mathrm{T} 1$ are the same in either case. 
Table 2 Factors

\begin{tabular}{|c|c|c|c|c|}
\hline FactorID & Factor & Value & $\begin{array}{l}\text { Value } \\
\text { ID }\end{array}$ & $\begin{array}{l}\text { Party } \\
\text { Favoured }\end{array}$ \\
\hline HP & $\begin{array}{l}\text { Hot } \\
\text { Pursuit }\end{array}$ & reward & $\mathrm{R}$ & Plaintiff \\
\hline $\mathrm{NC}$ & $\begin{array}{l}\text { Not } \\
\text { Caught }\end{array}$ & $\begin{array}{l}\text { Legal } \\
\text { Cer- } \\
\text { tainty }\end{array}$ & LC & Defendan \\
\hline OL & $\begin{array}{l}\text { Owned } \\
\text { land }\end{array}$ & $\begin{array}{l}\text { Legal } \\
\text { Cer- } \\
\text { tainty }\end{array}$ & LC & Plaintiff \\
\hline $\mathrm{C}$ & $\begin{array}{l}\text { Convention } \\
\text { Applies }\end{array}$ & $\begin{array}{l}\text { Legal } \\
\text { Cer- } \\
\text { tainty }\end{array}$ & LC & Plaintiff \\
\hline A & Assault & $\begin{array}{l}\text { Public } \\
\text { Order }\end{array}$ & $\mathrm{PO}$ & Plaintiff \\
\hline $\mathrm{N}$ & Nuisance & $\begin{array}{l}\text { Public } \\
\text { Order }\end{array}$ & $\mathrm{PO}$ & Plaintiff \\
\hline ID & Discourteous & $\begin{array}{l}\text { Public } \\
\text { Order }\end{array}$ & $\mathrm{PO}$ & Plaintiff \\
\hline $\mathrm{M}$ & Malicious & Fairness & $\mathrm{F}$ & Plaintiff \\
\hline DD & Discourteous & Fairness & $\mathrm{F}$ & Plaintiff \\
\hline B & Blameless & Fairness & $\mathrm{F}$ & Defendan \\
\hline EV & $\begin{array}{l}\text { Economicall } \\
\text { Valuable }\end{array}$ & yUtility & $\mathrm{U}$ & Plaintiff \\
\hline SV & $\begin{array}{l}\text { Socially } \\
\text { Valuable }\end{array}$ & Utility & $\mathrm{U}$ & Plaintiff \\
\hline PG & $\begin{array}{l}\text { Personal } \\
\text { Gain }\end{array}$ & Utility & $\mathrm{U}$ & Defendan \\
\hline
\end{tabular}

there are no factors in common with Keeble. Thus Popov can only argue that the assault was enough to favour him, claiming a preference for PO over LC.

T2

cases: (Popov,(HP,A,B)), (Pierson, (HP, ID, DD, SV)

factors: $\mathrm{NC}, \mathrm{HP}, \mathrm{A}$

rules: $\mathrm{NC} \rightarrow$ Defendant, $\mathrm{HP} \rightarrow$ Plaintiff, $\mathrm{A} \rightarrow$ Plaintiff

rule prefs: $\mathrm{A} \rightarrow$ Plaintiff $>\mathrm{HP} \rightarrow$ Plaintiff, $\mathrm{NC} \rightarrow$ Defendant $>\mathrm{HP} \rightarrow$ Plaintiff

value prefs: $\mathrm{PO}>\mathrm{LC}, \mathrm{LC}>\mathrm{R}$

It seems that this value preference was accepted. But Hayashi still has a factor and so can construct a third theory:

T3

cases: (Popov,(HP,A,B)), (Pierson, (NC, ID, DD, SV)

factors: $\mathrm{NC}, \mathrm{HP}, \mathrm{A}, \mathrm{B}$

rules: $\mathrm{NC} \rightarrow$ Defendant, $\mathrm{HP} \rightarrow$ Plaintiff, $\mathrm{A} \rightarrow$ Plaintiff, $\mathrm{B} \rightarrow$ Defendant

rule prefs: $\mathrm{B} \rightarrow$ Defendant $>\mathrm{A} \rightarrow$ Plaintiff, $\mathrm{A} \rightarrow$ Plaintiff $>\mathrm{NC} \rightarrow$ Defendant, $\mathrm{NC} \rightarrow$ Defendant $>$ $\mathrm{HP} \rightarrow$ Plaintiff

value prefs: $\mathrm{F}>\mathrm{PO}, \mathrm{PO}>\mathrm{LC}, \mathrm{LC}>\mathrm{R}$

If accepted, and the judge did identify fairness as his most important value, this would suggest a finding for Hayashi. But what did McCarthy decide? In fact McCarthy decided that it would be unfair to Popov to 
find for Hayashi, and unfair to Hayashi to find for Popov. He therefore chose to follow a quite different line based on the concept of equitable division (Helmholz, 1983). Using the principle of equitable decision, McCarthy's judgement was that the ball should be sold, and the proceeds divided equally between Popov and Hayashi. In this way, McCarthy seems to construe the rule arising from the innocence of Hayashi differently from the way it is construed in Theory T3, as something more like

$B \rightarrow \neg$ Plaintif $f$,

or perhaps even more like

$B \hookrightarrow$ Plaintif $f$,

where ' $\hookrightarrow$ ' is to be construed as a defeater in the sense of Defeasible Logic (DL) (e.g. (Johnston and Governatori, 2003)), that is a rule which blocks a conclusion, while not licensing the negation of that conclusion. This is interesting behaviour on the part of McCarthy, and may lend support to those who have argued that a logic like DL is more appropriate to legal reasoning than classical logic. We should, however, be wary of drawing this conclusion too quickly: B also applies in Ghen, where the case was decided for the plaintiff, and we would probably not wish to infer LC $>$ F from that case simply in order to be able to ignore the defeater. B takes on this role only when the inference was illegal, so perhaps the rule used by McCarthy is rather

$A \wedge B \hookrightarrow$ Plaintiff.

Note that we do not want the rule to be

$A \wedge B \rightarrow \neg(A \rightarrow$ Plaintif $f)$,

since we still need to use

$A \rightarrow$ Plaintiff

to prevent a finding for Hayashi. Perhaps McCarthy's rule is best expressed as

$A \wedge B \rightarrow((B \hookrightarrow$ Plaintiff $) \wedge(A \hookrightarrow$ Defendant $))$.

If this discussion is correct, and if McCarthy's position is a reasonable example of legal reasoning (his decision was not universally admired), then there are implications for approaches such as (BenchCapon and Sartor, 2003), and perhaps also for any factor based approach. First it seems difficult to capture McCarthy's understanding of the rule he is applying in terms of classical logic, which means that something more sophisticated than the simple logic used by (Bench-Capon and Sartor, 2003) is required. Secondly although some factors do behave in this way, others do not, and so factors can no longer be seen as homogeneous, and do not relate to rules in the straightforward way proposed by (Prakken and Sartor, 1998) and adopted by (Bench-Capon and Sartor, 2003). Moreover, one might consider whether this apparent heterogeneity of factors needs to be accommodated in CATO style approaches also. Indeed, in IBP (Brüninghaus and Ashley, 2005), a program developed from CATO, but which attempts to predict case outcomes rather than simply to generate relevant arguments, a distinction between factors was found to be required in order to be able to resolve conflicts appropriately. There the notion of knock-out factor was introduced. A knock-out factor is a factor so important that its presence is immediately decisive for the side it favours. This idea, however, does not help us when there are potentially knock-out factors on both sides, as in Popov. Moreover, as noted above, Blameless only takes on this significance in the presence of illegal interference: its effect seems to be to prevent Assault from acting as a knock out factor.

In the model of Popov in (Wyner et al., 2007), the problem is resolved by the use of arguments justifying refraining from an action, so that not deciding for the plaintiff is not equivalent to deciding for the defendant. This means that the answer set implementation of (Egly et al., 2008) finds justified arguments to not find for Popov and to not find for Hayashi. In (Egly et al., 2008) these arguments are instantiations of an argumentation scheme for practical reasoning and so no logic is explicitly used for forming as opposed to evaluating the arguments, but, if we were to render them using a logic, some mechanism such as the defeater of DL would seem necessary.

\section{Representation with Argumentation Schemes}

We will finish by looking at the cases using the reconstruction of CATO with Argumentation schemes as proposed in (Wyner and Bench-Capon, 2007). The idea of that paper was that an argument based on following a precedent could be presented as a cascade of argumentation schemes. The program works 
by comparing the factors present in the current case and a precedent and partitioning them according to whether there are present in both cases or only one. There are six partitions:

P1 : Plaintiff factors in both cases

P2 : Defendant factors in both cases

P3 : Plaintiff factors only in the current case

P4 : Defendant factors only in the precedent case

P5 : Defendant factors only in the current case

P6 : Plaintiff factors only in the precedent case

P3 and P4 weaken the current case, while P5 and P6 strengthen it.

They then give a number of argument schemes:

AS1: The main scheme, which argues that the current case should be decided in the same way as the precedent on the basis of their shared factors. The preference between factors is justified by A2 but is subject to an exception represented by AS4. This scheme favours the proponent (the plaintiff given the above partitions).

AS2: This states that the shared plaintiff factors were preferred to the shared defendant factors in the precedent. It is subject to an exception represented by AS3. It favours the proponent.

AS3: This says that the precedent was stronger for the plaintiff, on the basis of factors in P6. If, however, there are factors with the same value in the current case in P3, these may provide a counter argument. This attacks AS2 and so favours the opponent.

AS4: This says that the current case is stronger for the defendant on the basis of factors in P5. If, however, there are factors with the same value in P4, these can be used as a counter argument. This attacks AS1 and so favours the opponent.

AS5: This is an additional argument to find for the plaintiff based on strengths in the current case (factors in P3) not used in AS3. This provides additional support for the proponent.

AS6: This is an additional argument to find for the plaintiff based on weaknesses in the precedent case not (factors in P4) not used in AS4. This also provides additional support for the proponent.

Because we are not using dimensions the degree of support in not considered. For this purpose therefore we will use a pro-plaintiff and a pro-defendant factor relating to each of the five values. These are given below (pro-plaintiff first). The factors used in theory construction are given in brackets.

- Reward: MadeEfforts (i.e HP), or NoEffort (no example in cases).

- LegalCertainty: HadPossession (i.e. OL or C), NotCaught (i.e NC)

- PublicOrder: Illegallterference (i.e. A or N), LegitimateInteference (i.e ID)

- Fairness: Malice (i.e. M) or Acceptable(i.e. D or B)

- Utility: Valuable (i.e EV or SV) or NotValuable (i.e. PG)

We can now compare Popov with Keeble, to get the graph shown in Figure 1. The graph depicts the reasoning in the case a tree of argument schemes. The root is the claim that the case should be found for the plaintiff. The children of a claim node are the argument schemes which have been instantiated to support (in the case of solid arrows) or attack (in the case of open circles) it. The children of these scheme nodes are the premises (in the case of solid arrows) and any exceptions (in the case of open circles). Premises and exceptions may themselves be claims of further argument schemes. 


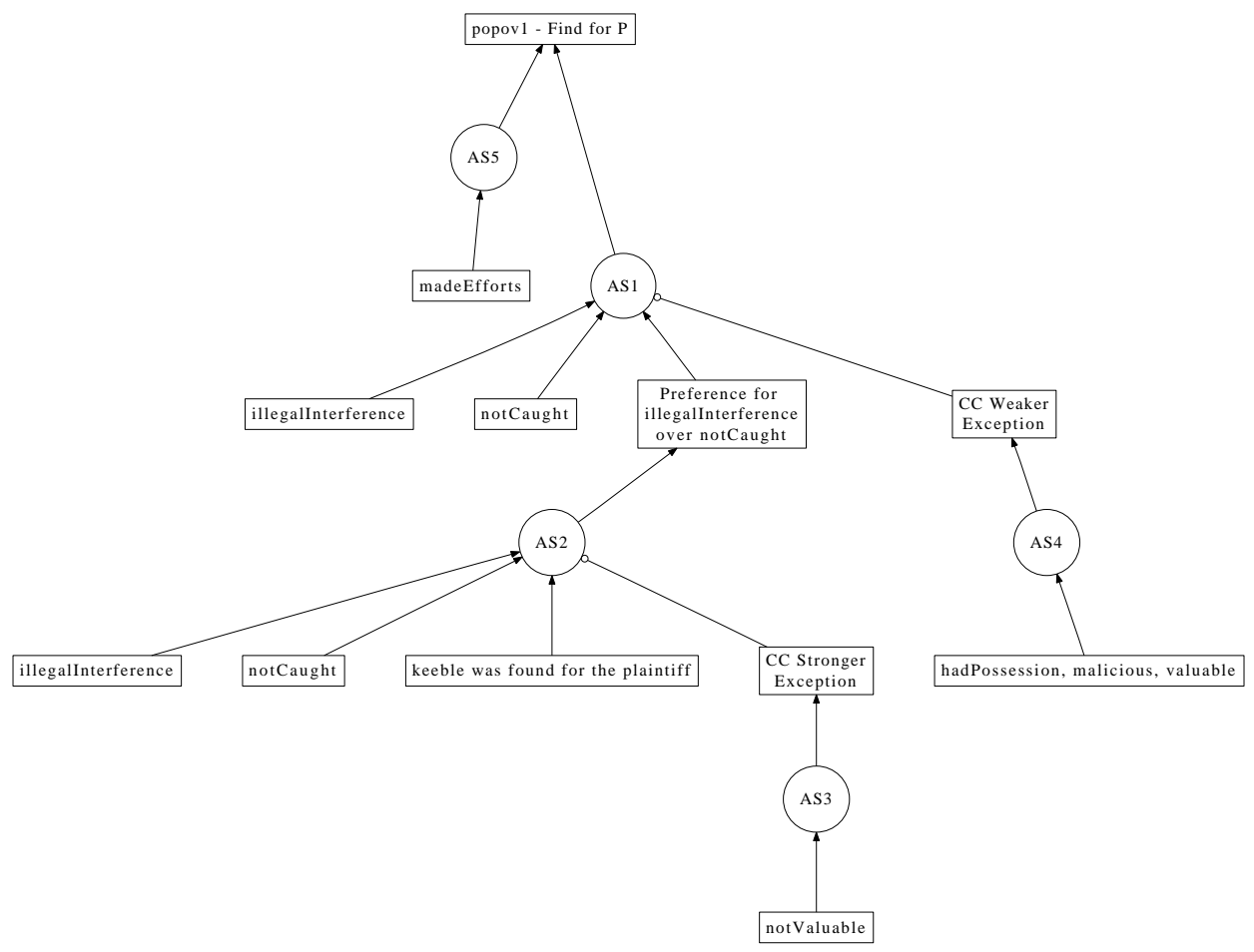

Figure 1: Argument Graph for Plaintiff in Popov citing Keeble

Here we can see the central argument, which is based on the preference for malicious interference over the fact that the animal was not caught, but attacked by the lack of utility in Popov's activity. But if we prefer Public Order to Utility, we may reject this counter argument. The argument is also problematic because Popov lacks the bad defendant motive, Keeble's valuable activity, and Keeble's possession claim based on land ownership ${ }^{8}$. In order to reject this, we must prefer Public Order to all the three values represented by these factors, even in combination. Finally we have an additional argument for Popov in that his efforts might deserve some reward.

A similar graph can be constructed to show the case for the defendant based on Young.

${ }^{8}$ Compare the three distinctions in the HYPO style treatment at the end of 3.2. 


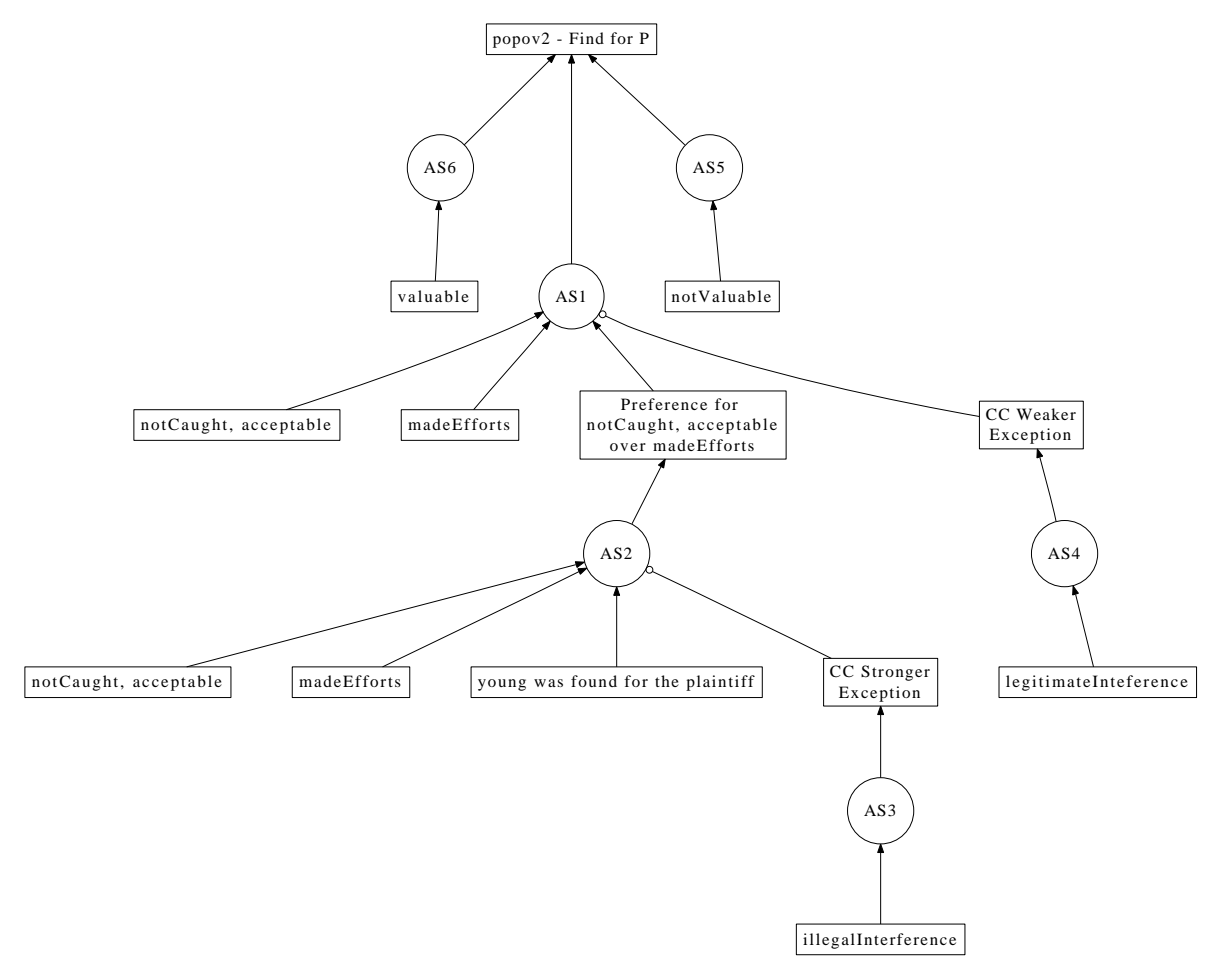

Figure 2: Argument Graph for Defendant in Popov citing Young

Note here that the validity of the argument turns on whether we give sufficient weight to Public Order to block the preference using either AS3 or AS4, but even if we do there are arguments available based on the valuable nature of Young's activity against the purely selfish gains sought by Popov. Taken together the two graphs imply that Public Order must be accorded supreme importance if Popov's case is to stand, and even this may not be sufficient to find for Popov. Public Order might be given this high importance if it were desired to send a clear message that impeding people attempting to catch valuable balls would be futile, since that person would be awarded the ball even if it were recovered by someone who himself did no wrong.

\section{Conclusion}

The above discussion has been intended to draw out a number of points relating to case representation:

1. That new cases may require us to reinterpret our analysis of precedent cases, throwing new light on how we should identify factors.

2. In consequence, systems such as HYPO and CATO, which presuppose an existing analysis, can best be applied in domains in which the case law is regarded as stable and relatively well understood. Even then, however, we need to be mindful that at some point a case may appear which upsets this stability, and so take care that a new case does not introduce a new issue that means that its strengths or weaknesses cannot be done justice by an existing analysis.

3. That the granularity of the analysis needs to be sufficiently fine if blurring important distinctions is to be avoided.

4. That it is possible that that theories should be seen in terms of some non-classical logic such as DL rather than in terms of classical logic, so that the notion of defeaters can be captured.

Use of dimensions and factors to explicate and model computational reasoning with legal cases, has been an important strand in AI and Law. The above analysis shows that some insights have been gained, even though it demonstrates the importance of the way in which the cases are represented in determining what will be produced. Moreover it points to some of the difficulties in producing a definitive representation, especially in advance of a new case. Additionally it indicates the importance 
of a phenomenon hinted at in the knock out factors of IBP, but deserving of a more systematic treatment, whereby the effect of some factors is not susceptible to a treatment using factors as premises of standard rules. This last would certainly merit further investigation.

\section{Acknowledgments}

I would like to thank the many people with whom I have discussed reasoning with cases in law over the many years, including Edwina Rissland, Henry Prakken, Giovanni Sartor, John Henderson, Alison Chorley, Katie Atkinson, Tom Gordon and Adam Wyner. Part of this work was supported by the Estrella (The European project for Standardized Transparent Representations in order to Extend Legal Accessibility (Estrella, IST-2004-027655)). This is especially true of the work in section 5, for which particular thanks to Adam Wyner, and Ken Chan, who wrote the GUI.

\section{References}

V. Aleven. Teaching Case Based Argumentation Through an Example and Models. Phd thesis, University of Pittsburgh, Pittsburgh, PA, USA, 1997.

K. D. Ashley. Modeling Legal Argument. MIT Press, Cambridge, MA, USA, 1990.

K. Atkinson, T. J. M. Bench-Capon, and P. McBurney. Arguing about cases as practical reasoning. In ICAIL, pages 35-44. ACM, 2005. ISBN 1-59593-081-7.

T. Bench-Capon and E. L. Rissland. Back to the future: dimensions revisited. In B. Verheij, A. Lodder, R. Loui, and A. Muntjewerff, editors, Proceedings of JURIX 2001, pages 41-52, Amsterdman, The Netherlands, 2001. IOS Press.

T. J. M. Bench-Capon. The missing link revisited: The role of teleology in representing legal argument. Artif. Intell. Law, 10(1-3):79-94, 2002.

T. J. M. Bench-Capon and G. Sartor. A model of legal reasoning with cases incorporating theories and values. Artif. Intell., 150(1-2):97-143, 2003.

B. R. Berger. It's not about the fox: the untold history of pierson v post. Duke Law Review, 55:1089-1135, 2006.

D. H. Berman and C. D. Hafner. Representing teleological structure in case-based legal reasoning: the missing link. In Proc. of the 4th ICAIL, pages 50-59. ACM Press, 1993.

D. H. Berman and C. D. Hafner. Understanding precedents in a temporal context of evolving legal doctrine. In ICAIL, pages 42-51, 1995.

S. Brüninghaus and K. D. Ashley. Generating legal arguments and predictions from case texts. In Proceedings of the 10th ICAIL, pages 65-74, 2005.

A. Chorley and T. J. M. Bench-Capon. An empirical investigation of reasoning with legal cases through theory construction and application. Artif. Intell. Law, 13(3-4):323-371, 2005.

U. Egly, S. A. Gaggl, and S. Woltran. Aspartix: Implementing argumentation frameworks using answerset programming. In M. G. de la Banda and E. Pontelli, editors, ICLP, volume 5366 of Lecture Notes in Computer Science, pages 734-738. Springer, 2008. ISBN 978-3-540-89981-5.

P. Finkelman. Fugitive baseballs and abandoned property: Who owns the home run ball? Cardozo Law Review, 23:1609-1633, 2002.

T. F. Gordon and D. Walton. Pierson vs. post revisited - a reconstruction using the carneades argumentation framework. In P. E. Dunne and T. J. M. Bench-Capon, editors, COMMA, volume 144 of Frontiers in Artificial Intelligence and Applications, pages 208-219. IOS Press, 2006. ISBN 978-1-58603-652-2. 
R. Helmholz. Equitable division and the law of finders. Fordham Law Review, 52(3):313-328, 1983.

J. Henderson and T. J. M. Bench-Capon. Dynamic arguments in a case law domain. In Proceedings of the 8th ICAIL, pages 60-69, 2001.

B. Johnston and G. Governatori. Induction of defeasible logic theories in the legal domain. In Proceedings of the Ninth ICAIL, pages 204-213, 2003.

E. H. Levi. An Introduction to Legal Reasoning. University of Chicago Press., Chicago, Ill, USA, 1948.

A. R. Lodder and L. Mommers, editors. Legal Knowledge and Information Systems - JURIX 2007: The Twentieth Annual Conference on Legal Knowledge and Information Systems, Leiden, The Netherlands, 12-15 December 2007, volume 165 of Frontiers in Artificial Intelligence and Applications, 2007. IOS Press. ISBN 978-1-58603-810-6.

H. Prakken. An exercise in formalising teleological case-based reasoning. Artif. Intell. Law, 10(1-3): 113-133, 2002.

H. Prakken and G. Sartor. Modelling reasoning with precedents in a formal dialogue game. Artif. Intell. Law, 6(2-4):231-287, 1998.

E. L. Rissland. Examples in legal reasoning: Legal hypotheticals. In IJCAI, pages 90-93, 1983.

E. L. Rissland and K. D. Ashley. A note on dimensions and factors. Artif. Intell. Law, 10(1-3):65-77, 2002.

E. L. Rissland and M. T. Friedman. Detecting change in legal concepts. In Proceedings of the 5th ICAIL, pages $127-136,1995$.

G. Sartor. Teleological arguments and theory-based dialectics. Artif. Intell. Law, 10(1-3):95-112, 2002.

A. Z. Wyner and T. J. M. Bench-Capon. Argument schemes for legal case-based reasoning. In Lodder and Mommers (2007), pages 139-149. ISBN 978-1-58603-810-6.

A. Z. Wyner, T. J. M. Bench-Capon, and K. Atkinson. Arguments, values and baseballs: Representation of popov v. hayashi. In Lodder and Mommers (2007), pages 151-160. ISBN 978-1-58603-810-6. 